\title{
Performance evaluation of different structures of power system stabilizers
}

\author{
M. Balasubbareddy ${ }^{1}$, G. V. K. Murthy ${ }^{2}$, K. Sowjan Kumar ${ }^{3}$ \\ ${ }^{1}$ Chaitanya Bharathi Institute of Technology, India \\ ${ }^{2}$ Department of EEE, PACE Institute of Technology and Sciences, India \\ ${ }^{3}$ Department of EEE, SSN Engineering College, India
}

\begin{tabular}{l} 
Article Info \\
\hline Article history: \\
Received Jan 6, 2019 \\
Revised Jun 20, 2020 \\
Accepted Jul 13, 2020 \\
\hline
\end{tabular}

\section{Keywords:}

Excitation

Multi machine system

Oscillations

PSS

Single machine system

Stability

\begin{abstract}
The electric power from the system should be reliable and economical for consumer's equipment satisfaction. An electric power system consists of many generators, transformers, transmission lines, loads, etc. For the power system network, dynamic performance and stability are important. The system is lost its stability by some disturbances i.e., load variations, generator failure, prime mover failure, transmission line outage, etc. Whenever load variations in the system, generator rotor speed will vary, means oscillations in the rotor speed, which is deviating from rated speed. The excitation system will control the generator rated line voltage. When fault occurs at any equipment in the system, the system will unstable. If fault occurs at generator, the generator oscillates. To reduce the oscillations and to make the system stable used power system stabilizers (PSS's). Here, three types of PSS's are used i.e., PSS1B, PSS2B, PSS4B. Comparisons of three PSS's are on the multi machine system under some disturbance. From the observations, concluding that PSS4B is quickly control the oscillations in the physical parameters of machine in the system than other power system stabilizers.
\end{abstract}

This is an open access article under the CC BY-SA license.

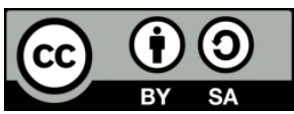

\section{Corresponding Author:}

M. Balasubbareddy,

Chaitanya Bharathi Institute of Technology,

Hyderabad, Telangana, India.

Email: balasubbareddy79@gmail.com

\section{INTRODUCTION}

Modern power system is interconnected with multiple machines, transformers, transmissionlines, loads. The supply should be reliable and economical electric energy is major requirement of industrial progress and consequent rise in the standard of living. The frequency and voltage should be held within allowable tolerances to satisfy consumer's equipment operation. With Deregulation of power supply system, Power transmitting to various places wherever it is required. Here, dynamic performance and stability are important. The system lost its stability under certain faults i.e.generator failure, prime mover failure, transmission line outage, load variations, etc. These disturbances affect the power system variables such as frequency and voltage this leads to instability of the system. The stability is defined as when a disturbance occurs in the electric power system, the system regains its original state after the disturbance [1, 2]. The stability problem is related with the behavior of the synchronous machines under disturbed conditions. When the system changes its operating point from one stable point to the other, it is mandatory that all interconnected synchronous machines should remain in synchronism. i.e., machines should connect in parallel with same speed [3]. In [4] this, proposed new polymorphic bacterial chemotaxis optimization 
algorithm to optimize the PSS parameters. In [5, 6] proposed new power system stabilizer for multi-mode damping problem, he aims to analyze performance in tracing of system problems. In [7] this some of modern voltage regulator ystems are used the PID controller for stabilization. In [8] this described the power system analysis software package (PSASP) for dynamic stability of small disturbance. In [9-10] this described multi machine power system analysis using new design of fixed parameter decentralizes.

Power system stabilizer (PSS) is maintains systemstability after a disturbance in the system. It is making system as stable by controlling the oscillations in the system during the fault. The oscillations mainly producing from generator rotor speed. It is leading to development of more damped torque, which is unfavorable to quality of supply [11]. In [12] this, authors are described the transient stability analysis and also described a method for estimating a normalized power system transient stability of a power system.Previously, PSS1B and PSS2B are designed to improve the power system stability.PSS used in power companies because it is simple in structure, flexible an easy to implement.PSS will improve the system performance during the disturbance. Both single input and dual input stabilizers are used to damp out oscillations in the system. Dual input is used with combination of shaft speed deviation and change in electric power is advantageous compared to single input [13-25]. The target of this paper is implementation of power system stabilizer with physical parameters in single machine infinite bus system. Effect of power system stabilizer implementation on system damping is targeted. Further for multi machine power system, aimed that the damping of power system oscillations can achieved with minimum number of power system stabilizers located at optimal locations. The PSS4B will reduce the oscillations in physical parameters of machine in a system during the fault. The PSS4B will take less time to make the machine stable compared to other power system stabilizers.

\section{SINGLE MACHINE INFINITE BUS SYSTEM}

Machines are connected through a transmission lines. In general synchronous machines are expressed [2] as follows:

$$
\begin{aligned}
& \Delta \dot{\omega}=\frac{\Delta T m}{2 H}-\frac{K 1}{2 H} \Delta \delta-\frac{K 2}{2 H} \Delta E_{q}^{\prime}-\frac{D}{2 H} \Delta \omega ; \Delta \delta^{\prime}=\omega_{b} \Delta \omega \\
& \Delta E_{q}^{\prime}=-\frac{1}{K 3 T_{d 0}{ }^{\prime}} \Delta E_{q}^{\prime}+\frac{1}{T_{d 0}{ }^{\prime}} \Delta E_{f d}-\frac{K 4}{T_{d 0}{ }^{\prime}} \Delta \delta ; E_{f d}^{\prime}=-\frac{1}{T_{a}}\left(K_{a} K 5 \Delta \delta+K_{a} K 6 E_{q}^{\prime}+E_{f d}\right)
\end{aligned}
$$

The constants (K1-K6) are Heffron-Phillips constants are computed by using this data Generator:

$$
M=2 \times H=9.26 ; \quad T_{d o}{ }^{\prime}=7.76 ; \quad D=0 ; \quad X_{d}=0.973 ; \quad X_{d}{ }^{\prime}=0.190 ; \quad X_{q}=0.550
$$

Excitation: $K_{A}=50 \& T_{A}=0.05 ;$ Line and load: $\mathrm{R}=-0.034, \mathrm{X}=0.997 ; \mathrm{G}=0.249, \mathrm{~B}=0.262$

Initial state: $P_{a 0}=1.0, Q_{e 0}=0.015, V_{t 0}=1.05$

Machine Modeling K1 to K6 Constants:

$$
\begin{aligned}
& K_{1}=F_{d}\left(X_{q}-X_{d}^{\prime}\right) I_{q o}+F_{q}\left[\left(E_{q o}{ }^{\prime}+\left(X_{q}-X_{d}^{\prime}\right) I_{d 0}\right]\right. \\
& K_{2}=I_{q o}+Y_{d}\left(X_{q}-X_{d}^{\prime}\right) I_{q o}+Y_{q}\left[\left(E_{q o}^{\prime}+\left(X_{q}-X_{d}^{\prime}\right) I_{d o}\right]\right. \\
& K_{3}=\frac{1}{\left[1+\left(X_{d}-X_{d}^{\prime}\right) Y_{d}\right]} ; K_{4}=\left(X_{d-}-X_{d}^{\prime}\right) F_{d} ; K_{5}=F_{d}\left(\frac{-X_{d}^{\prime} V_{q o}}{V_{t o}}\right)+F_{q}\left(\frac{X_{q} V_{d o}}{V_{t o}}\right) \\
& K_{6}=\left(V_{q o} / V_{t o}\right)+V_{d}\left(\frac{-X_{d}^{\prime} V_{q o}}{V_{t o}}\right)+Y_{q}\left(\frac{X_{q} V_{d o}}{V_{t o}}\right)
\end{aligned}
$$

The Heffron-Phillips constants are dependent on operating conditions and machine parameters considered for the system. Here, $\mathrm{K} 1, \mathrm{~K} 2, \mathrm{~K} 3, \mathrm{~K} 4, \mathrm{~K} 6$ are positive and $\mathrm{K} 5$ is negative. 


\section{POWER SYSTEM STABILIZER}

In an interconnected power system arises the low frequency oscillations with less time durations, then system will stops working completely. The system shut down due to unavailability to compress those oscillations in the system. In order to overcome this problem, PSS is tested and implemented to compensate those oscillations. PSS Figure 1 is a supplementary control connected to the excitation system. The feedback signal is connected in such a way that rotor electric torque in phase with speed variations. The PSS parameters are tuned with system conditions, otherwise system will be in unstable state. The Block Diagram of PSS is shown in Figure 1.

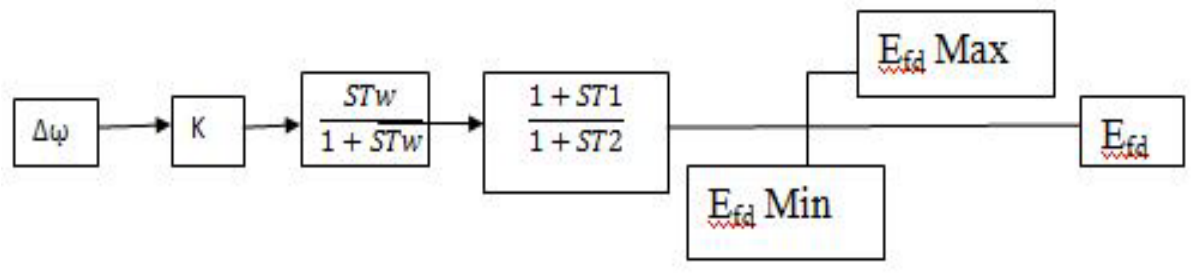

Figure 1. Power system stabilizer

PSS classified based on the input: The shaft speed deviation, change in accelerating power and Change in frequency. PSS consists of gain, washout block and lead-lag compensator. The gain related to damping introduced by the stabilizer. Then increasing gain moves unstable mode to stable mode. Gain should be set corresponding to maximum damping. Washoutis high pass filter, this will block the offsets and responds for speed oscillations. This also controls the terminal voltage deviations from normal voltage of the generator. Phase Compensationis a Lead-lag compensator. The lead-lag compensator is tuned in such way that speed oscillations give damping torque on the rotor. When Terminal voltage is changed, the PSS affect the generator power flow. The terminal voltage is limited under AVR variations.

\subsection{Types of power system stabilizers}

Single input PSS: The inputs which are given to PSS are change in rotor speed $(\Delta \omega)$, the change in frequency $(\Delta \mathrm{f})$ and the accelerating power $(\Delta \mathrm{Pa})$. PSS1B has change in rotor speed as input. This stabilizer will reduce the damping of the low frequency oscillations. The structure of PSS is in the form as, for which the parameter such as stabilizer gain Kc, lead lag time constants T1 and T2 are to be computed such that overall system is stable when PSS included in feedback loop.

Dual input PSS(PSS2B): In this PSS, one input as change in rotor speed and another input as change in electric power. The change in electric power $(\Delta \mathrm{Pe})$ : Due to simplicity of measuring electric power and relationship to shaft speed, as an input signal to stabilizer. This stabilizer uses electric power $(\Delta \mathrm{Pe})$ as input and it has stabilizer parameters $\mathrm{K}$ and $\mathrm{T}$ are to be computed, which are related to stability of the system. The block diagram of PSS2B is shown in Figure 2.

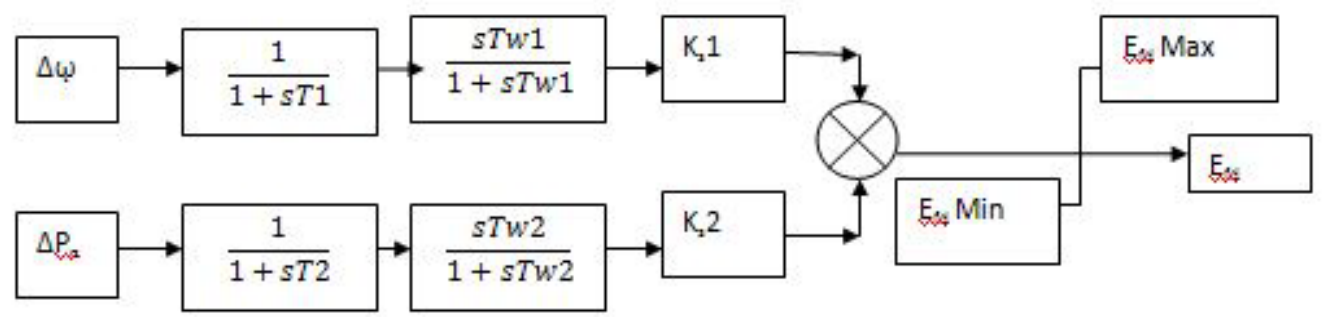

Figure 2. PSS2B

Multi band stabilizer (PSS4B): In the MB-PSS controls the three ranges of frequencies, which are low, intermediate and high frequency ranges, the stabilizer dampens local and inter-area oscillations. The disturbances created in the electromechanical interconnected power system; they create oscillations in 
the generator of a system. Local oscillations are created by disturbances that occur between one stable generator and unstable generator in a power station. The local oscillations frequency range is $0.8 \mathrm{~Hz}$ to $4.0 \mathrm{~Hz}$. Inter- area oscillations are caused by a disturbance between two areas of generation satiations in the power system. The range of frequency is $0.2 \mathrm{~Hz}$ to $0.8 \mathrm{~Hz}$. MB PSS oscillation damping three ranges of different frequencies to dampen entire spectrum frequency oscillation that can occur in the power system achieved. Low and medium frequency oscillations related to inter-area mode, high frequency oscillation related to local mode.

\section{RESULTS AND ANALYSIS}

\subsection{Single machine power system}

Generator data: Rated MVA: 777MVA; Rated Voltage: $21 \mathrm{kv} ; \mathrm{H}$ (Inertia)= 4.4KW-Sec/KVA; The mechanical power input $=1$ p.u.; Excitation voltage $=1$ p.u; $\mathrm{f}=50 \mathrm{~Hz}$; Poles $=4$; Rated speed $=1$ p.u. (base speed $=1500 \mathrm{rpm}$ ). Under no-load conditions, the single machine system maintains rated speed as $1 \mathrm{p} . \mathrm{u}$. From Figure 3, when a three-fault created at load side from $0 \mathrm{sec}$ to $1.06 \mathrm{sec}$, the generator becomes unstable. The generator speed oscillates (deviates from 1p.u.). In order to control the oscillations in generator speed used power system stabilizer (PSS). Here, using three different PSS's (PSS1B, PSS2B, PSS4B). In Figure 4, the power system stabilizer is connected to excitation system. The output of power system stabilizer is connected to input of excitation system. The PSS will control oscillations in physical parameters of machine in the system.

From the Figure 5, without PSS the generator rotor speed oscillates. The magnitude of rotor speed increased from 1p.u. to 1.017p.u. With PSS1B, The generator rotor speed decreased from 1.013p.u. To 1p.u. and reached its steady state within 6sec. With PSS2B, the generator rotor speed decreased from 1.007p.u. To 1p.u. and reached its steady state within 5.2sec. With PSS4B, the generator rotor speed decreased from 1.003p.u. To 1p.u. and reached its steady state within 5sec.So, PSS4B will reduce the Generator rotor speed oscillations in a less time compared to other PSS's.

\subsection{Comparison of results}

From the Table 1, Without PSS, the generator speed is increased to 1.017p.u., and it is settles at $7 \mathrm{sec}$. For different stabilizers, the generator rotor speed increased in magnitude with steady state time. PSS4B settles in less time.

Continuous

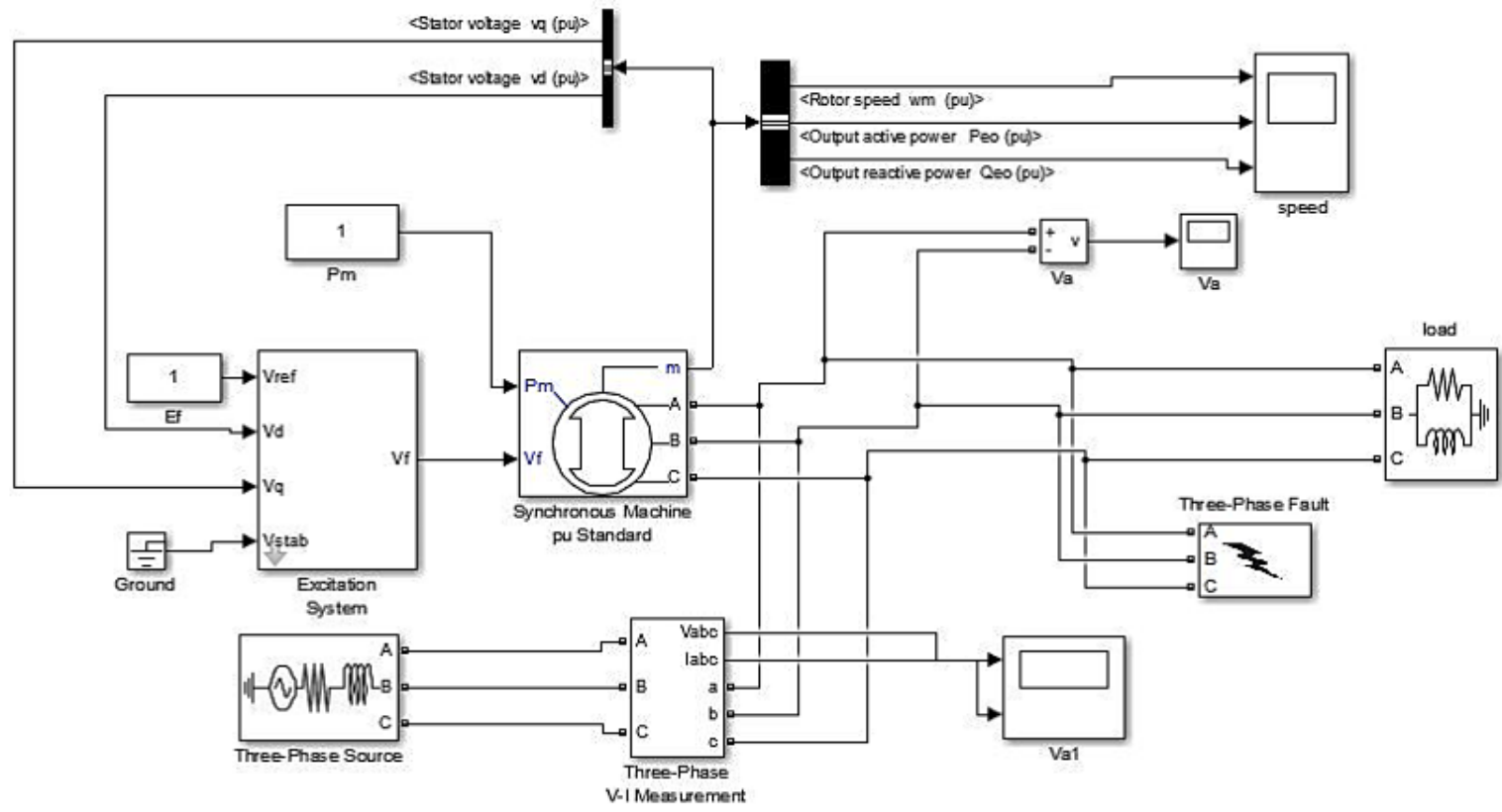

Figure 3. Single machine infinite bus during fault without PSS 


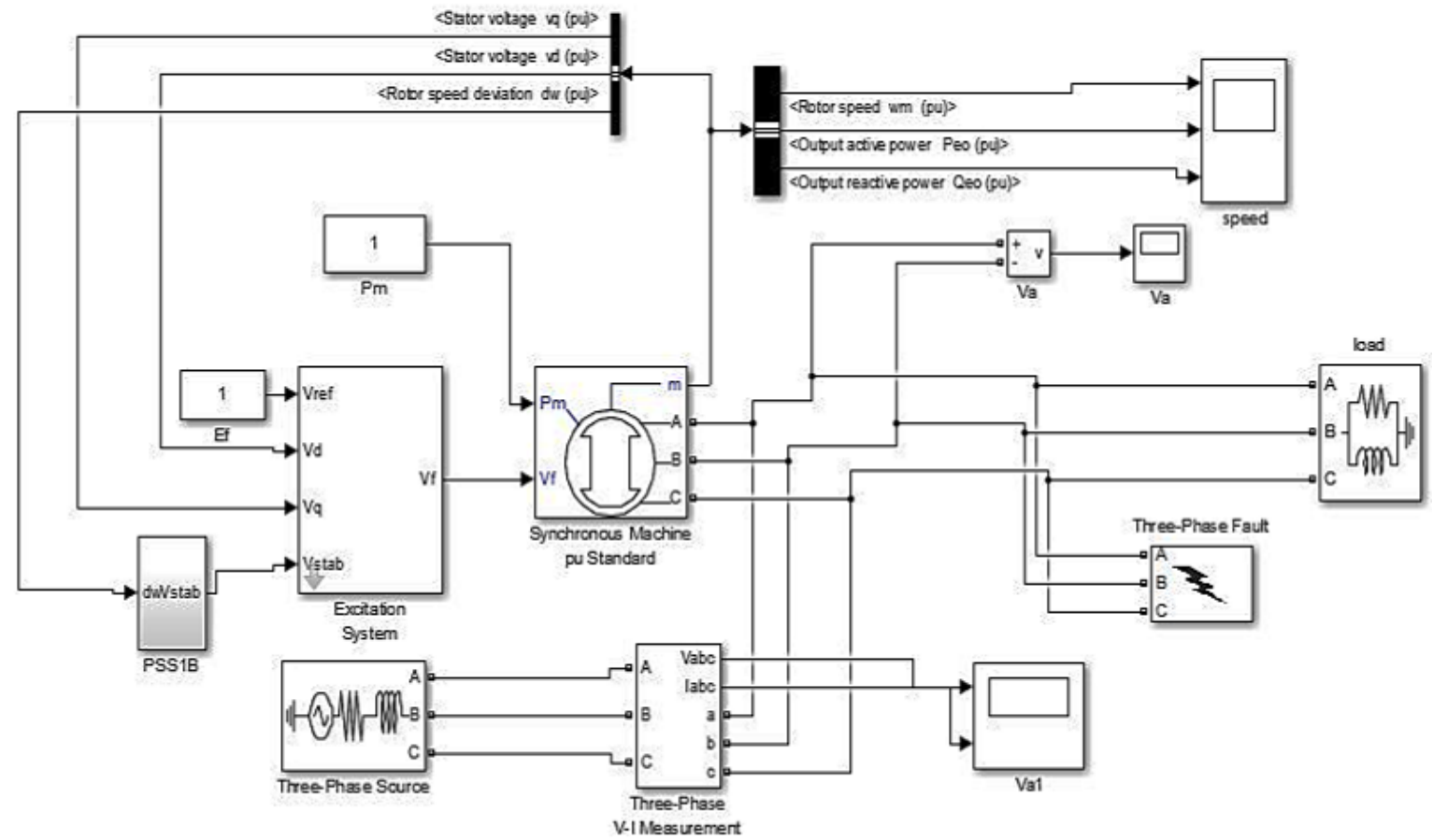

Figure 4. Single machine infinite bus with PSS

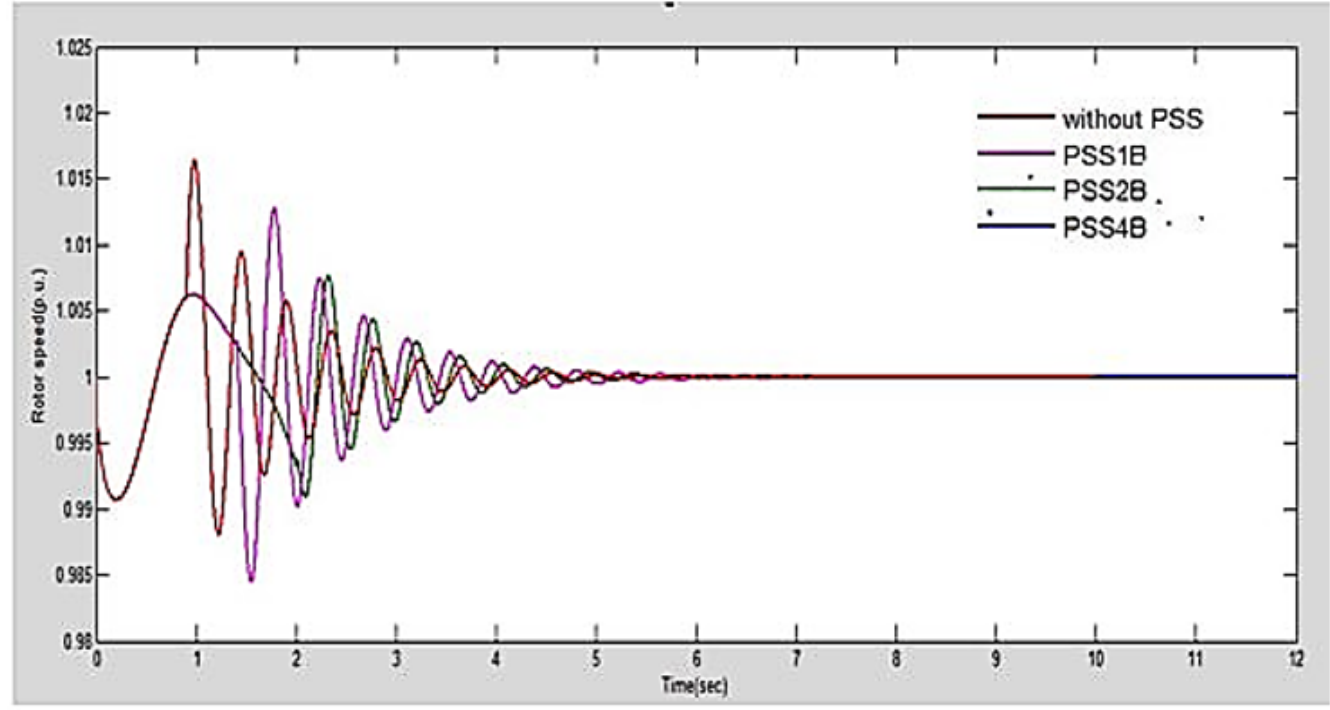

Figure 5. Comparison of three power system stabilizers on single machine infinite bus system

Table 1. Comparison of three power system stabilizers

\begin{tabular}{ccc}
\hline & Generator Rotor speed increased magnitude (p.u) & Steady state time (see) \\
\hline Without PSS & 1.017 & 7 \\
PSS1B & 1.013 & 6 \\
PSS2B & 1.007 & 5.2 \\
PSS4B & 1.003 & 5 \\
\hline
\end{tabular}




\subsection{Multi machine system}

Multi machine system Data: Buses-11, lines-7, generators-4, transformers-4, loads-2

Generator data: 900MVA, $21 \mathrm{kV}, 50 \mathrm{~Hz}$;

$$
\begin{aligned}
& X_{d}=1.8 \text { p.u., } X_{d}^{\prime}=0.3 p . u ., X_{d}^{\prime \prime}=0.25 \text { p.u.; } X_{q}=1.7 p . u ., X_{q}^{\prime}=0.55 \text { p.u.; } \\
& X_{q}^{\prime \prime}=0.25 \text { p.u.; } X_{l}=0.2 p . u . ; T_{d o}{ }^{\prime}=8, T_{d o}^{\prime \prime}=0.03, T_{q o}=0.4, T_{q o}{ }^{\prime \prime}=0.05
\end{aligned}
$$

Transformer data: 950MVA, $21 \mathrm{KV} / 4000 \mathrm{kV}$

Distributed Line Parameter data: $\mathrm{D}=25 \mathrm{Km}, \mathrm{r}=0.0529 \Omega / \mathrm{Km}, \mathrm{L}=0.0014 \mathrm{H} / \mathrm{Km}, \mathrm{C}=8.7748 \mathrm{nF} / \mathrm{Km}$, Load data: Load 1: $\mathrm{P}=967 \mathrm{MW}, \mathrm{Q}=287 \mathrm{Mvar}$, Load 2: $\mathrm{P}=1767 \mathrm{MW}, \mathrm{Q}=437 \mathrm{Mvar}$

Excitation System data: $\mathrm{Tr}=0.02, \mathrm{~Tb} 1=37.5, \mathrm{Tc} 1=1.5, \mathrm{~Tb} 1=0.15, \mathrm{Kr}=170, \mathrm{Ef} 1=+14.55, \mathrm{Ef} 2=-14.55$, $\mathrm{Te}=1.706, \mathrm{Ke}=1$, Saturation limits of Efd are 1.2p.u to 1.6 p.u

PSS1B data: for $\Delta \omega$ input $\mathrm{T} 1=0.05 \mathrm{~s}, \mathrm{~T} 2=0.02 \mathrm{~s}, \mathrm{~T} 3=3 \mathrm{~s}, \mathrm{~T} 4=5.4 \mathrm{~s}, \mathrm{Tw}=10 \mathrm{~s}, \mathrm{Gain}(\mathrm{K})=30$ Limits of Uss $1=-0.15$ to 0.15

PSS2B data: For $\Delta \omega$ input (same as above) for $\Delta \mathrm{Pa}$ input, $\mathrm{T} 1=0.06 \mathrm{~s}, \mathrm{~T} 2=1 \mathrm{~s}, \mathrm{~T} 3=0 \mathrm{~s}, \mathrm{~T} 4=0 \mathrm{~s}, \mathrm{Tw}=1 \mathrm{~s}$, Gain $(\mathrm{K})=3.125$, limits of $\mathrm{U}_{\mathrm{ss} 1}=-0.15$ to 0.15

PSS4B data: Gain=1, $F_{L}=0.2 \mathrm{~Hz}, \mathrm{~K}_{\mathrm{L}}=30, \mathrm{~F}_{\mathrm{I}}=1.25 \mathrm{~Hz}, \mathrm{~K}_{\mathrm{I}}=40, \mathrm{~F}_{\mathrm{H}}=12 \mathrm{~Hz}, \mathrm{~K}_{\mathrm{H}}=160, \mathrm{~V}_{\mathrm{Lmax}}=0.075$, $\mathrm{V}_{\text {Imax }}=0.15, \mathrm{~V}_{\text {Hmax }}=0.15, \mathrm{~V}_{\text {Smax }}=0.15$

In Figure 6 multi machine system consists of generators, transmission lines, transformers, loads, etc

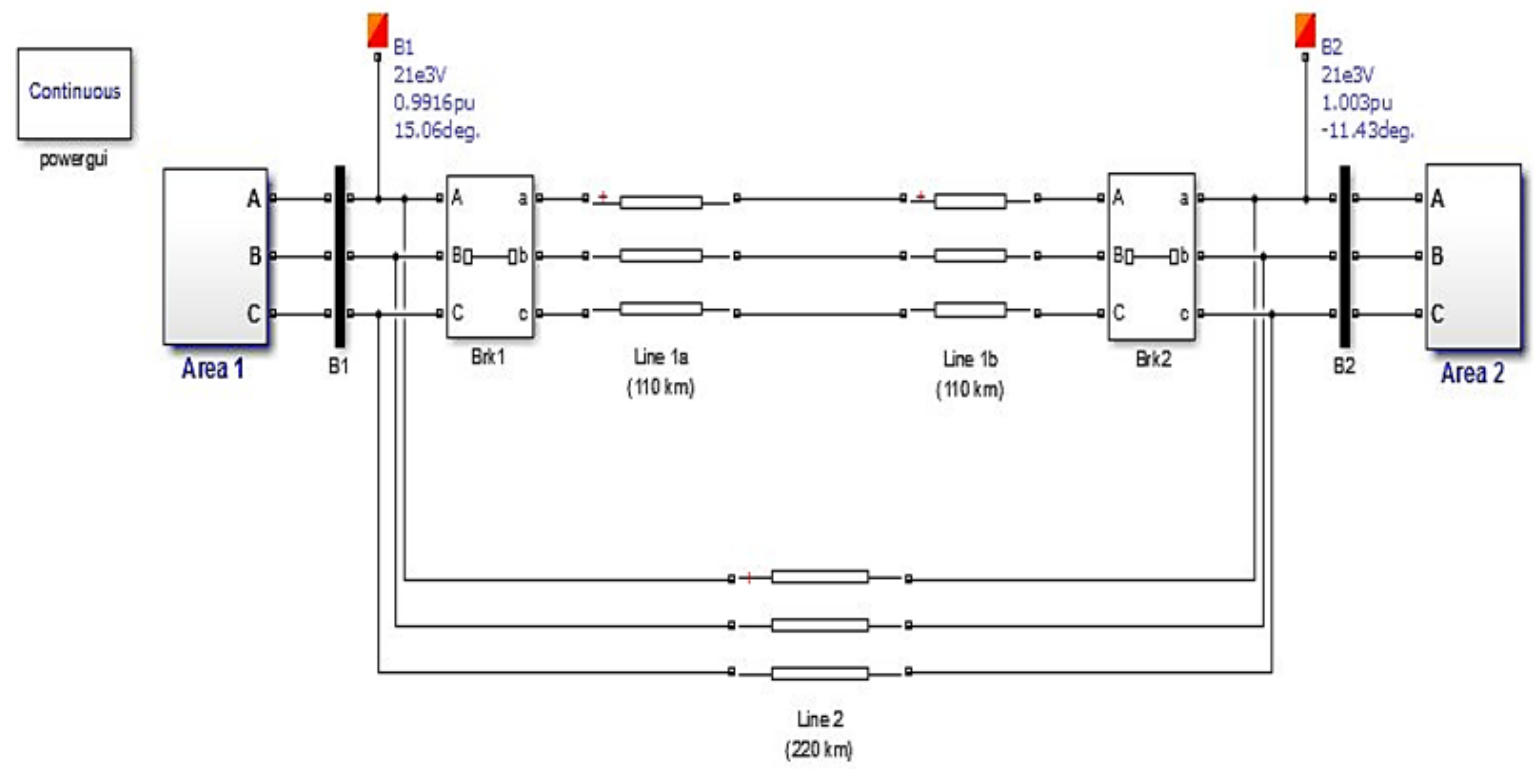

Figure 6. Simulation diagram of multi machine system

In Figure 7, inside the area1, two generators, two transformers with load are connected. The threephase fault created at generator 1 . Similarly generators, transformers, etc there in inside area 2. Figure 8 inside every machine is connected with excitation system and different power system stabilizers. The excitation system maintains the rated voltage of generator. The PSS will reduce the oscillations and retains the system stability. When three phase faults created at generator 1 from $0.005 \mathrm{sec}$ to $0.007 \mathrm{sec}$. Then all generators in system became unstable. Means, initially the generator rotor speed is $12 \mathrm{p} . \mathrm{u}$. After the fault, all generator speeds deviate from 12p.u.

From Figure 9, the magnitude of rotor speed reduced to 0p.u.the generator becomes unstable. Form Figure 10, generator2 (without PSS) is unstable, rotor speed reduced from 12p.u. to 0p.u. With PSS1B, initially it is unstable. Rotor speed retains its steady state $12 \mathrm{p} . \mathrm{u}$. within $0.024 \mathrm{sec}$. With PSS2B, Rotor speed retains its steady state 12 p.u. within $0.022 \mathrm{sec}$. With PSS4B, Rotor speed retains its steady state $12 \mathrm{p} . \mathrm{u}$. within $0.008 \mathrm{sec}$.

From Figure 11, generator3 (without PSS) is unstable, rotor speed reduced from 12p.u. to 0p.u. With PSS1B, initially it is unstable. Rotor speed retains its steady state $12 \mathrm{p} . \mathrm{u}$. within 0.029 sec. With PSS2B, Rotor 
speed retains its steady state 12 p.u. within $0.027 \mathrm{sec}$. With PSS4B, Rotor speed retains its steady state 12 p.u. within $0.021 \mathrm{sec}$

From Figure 12, Generator 4 (without PSS) is unstable, rotor speed reduced from 12p.u. to 0p.u. With PSS1B, initially it is unstable. Rotor speed retains its steady state 12 p.u. within $0.03 \mathrm{sec}$. With PSS2B, Rotor speed retains its steady state 12 p.u. within $0.026 \mathrm{sec}$. With PSS4B, Rotor speed retains its steady state 12 p.u. within $0.021 \mathrm{sec}$. From the above results, we can observe that when a three-phase fault created at generator1, all the generator rotor speeds are decreased from 12p.u. to 0p.u. and Generators are stopped working, they can't supply power to load. It is also observed that generator1 still unstable by connecting different PSS stabilizers. Generator2 becomes stable with PSS4B in less time $0.008 \mathrm{sec}$. Generator 3 becomes stable with PSS4B in less time $0.021 \mathrm{sec}$. Generator3 becomes stable with PSS4B in less time $0.021 \mathrm{sec}$

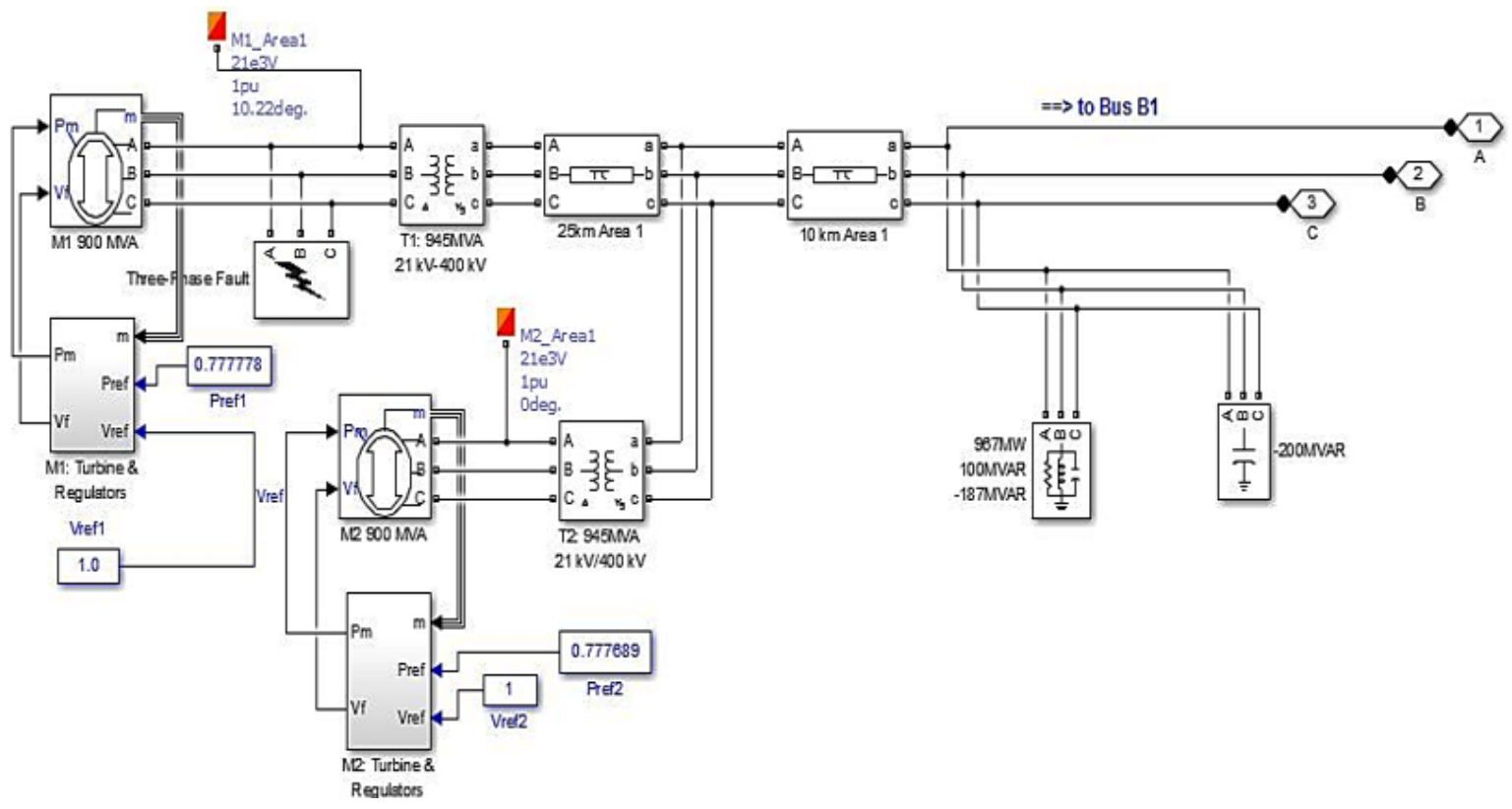

Figure 7. Inside area1

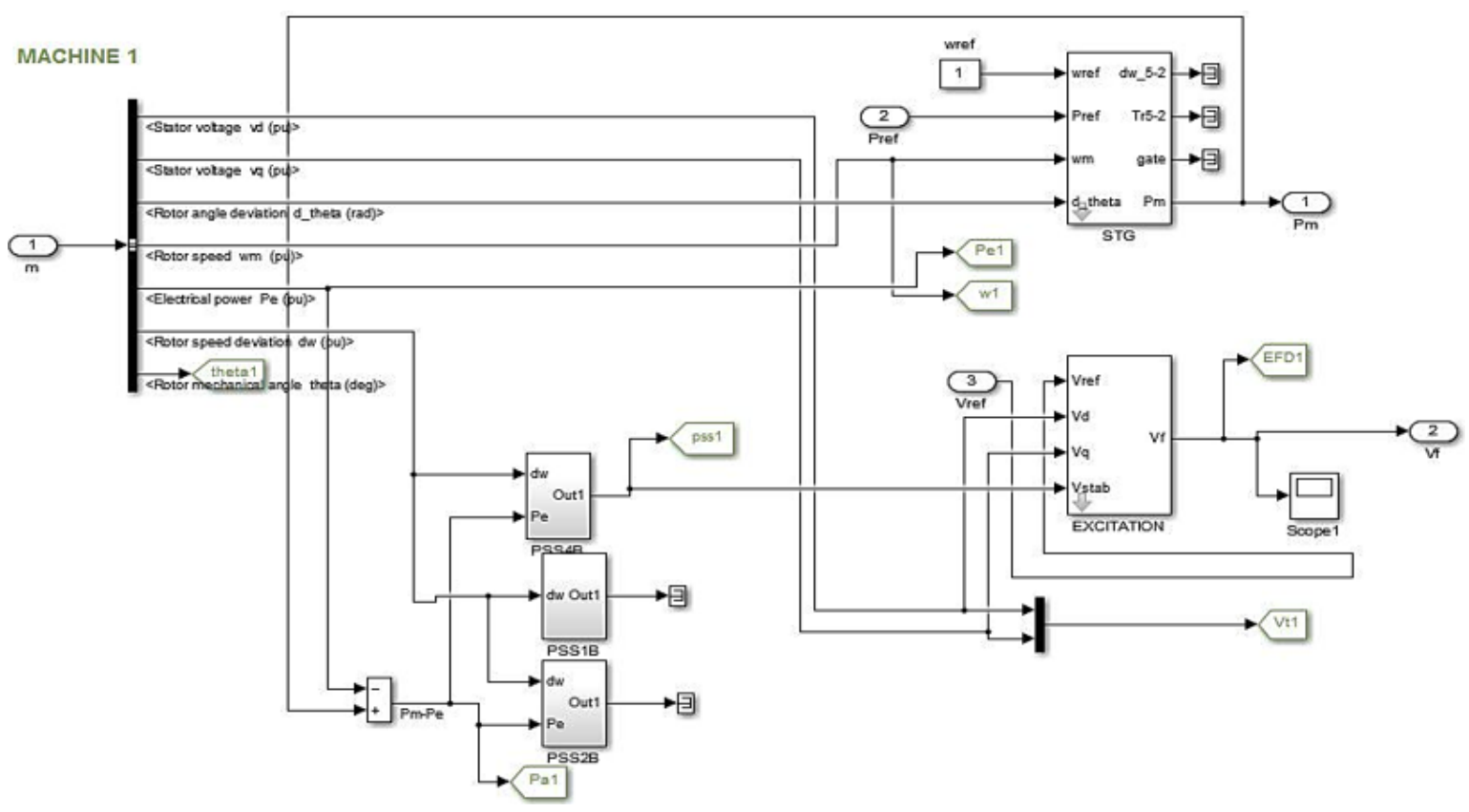

Figure 8. Inside every machine 


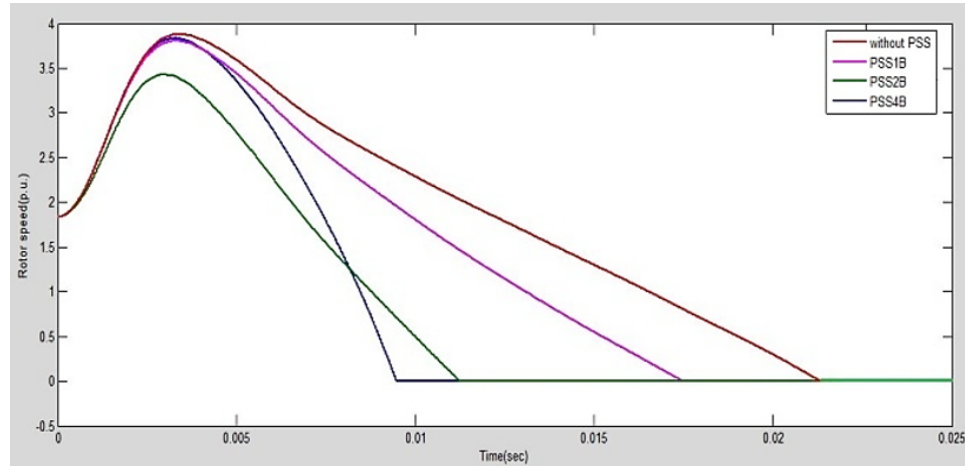

Figure 9. Performance of generator1 under three phase faults at generator 1

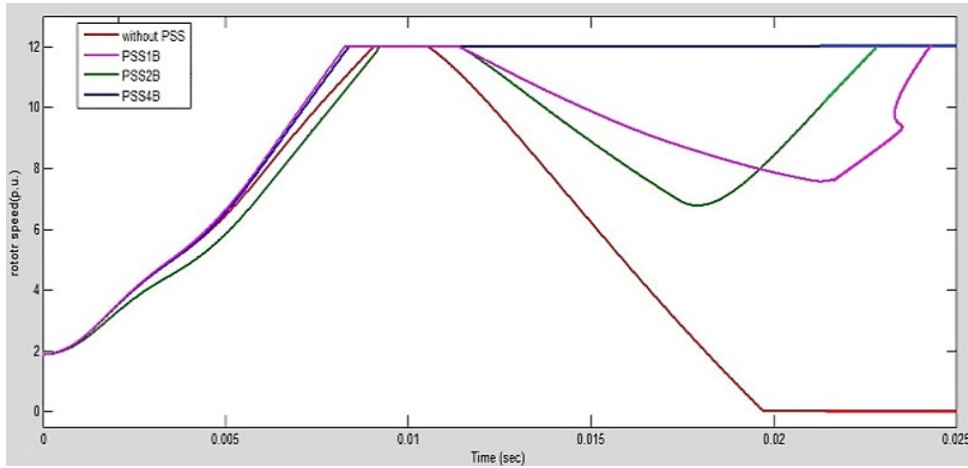

Figure 10. Performance of generator2 under three phase faults at generator1

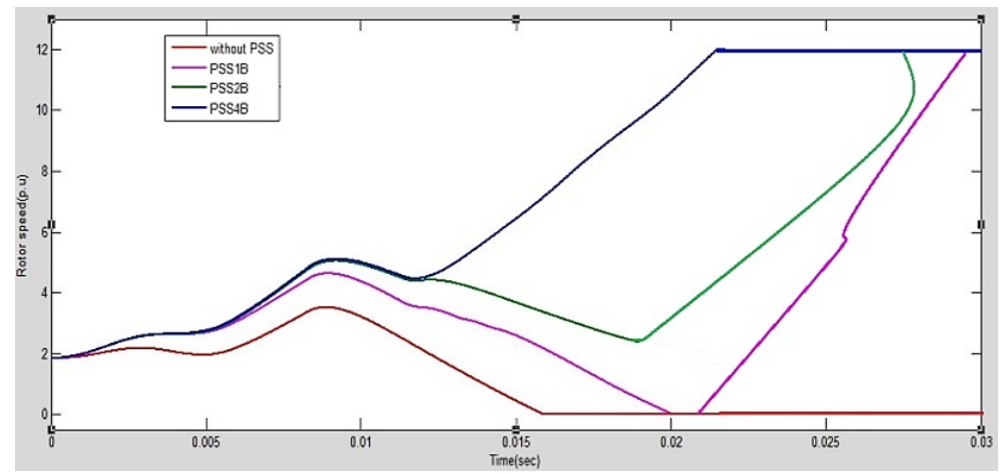

Figure 11. Performance of generator3 under three phase faults at generator1

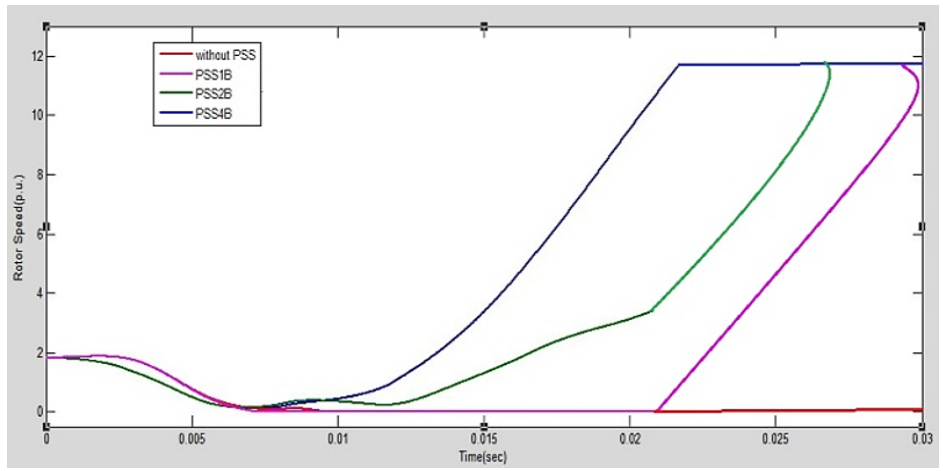

Figure 12. Performance of generator4 under three phase faults at generator1 


\section{CONCLUSION}

PSS is additional controlretain the steady state of single machine infinite bus system under large disturbance from unstable state. From the simulation results, can observe that PSS will reduce the amplitude of damping oscillations, improve the transient stability of the power system. With PSS application on the multi machine system is under the disturbance, the results shown with various PSS's applied on the system. Compared the results of three PSS's under three phase faults in the system. Primarily the state of the system facing three phase faults at generator1, all the generators in the system are unstable. When PSS introduced in the system, it will dampen the oscillations of physical parameters of generators and make the generators 2, 3, and 4 are stable. PSS4B will reduce the oscillations in less time in all the generators of system compared to other PSS's (PSS1B, PSS2B)

\section{ACKNOWLEDGEMENTS}

There are several people we would like to thank. First, we would like to thank Management, principal of ChaitanyaBharathi Institute of Technology, Hyderabad, India for his encouragement and support and providing us with the facility for completing this research work.

\section{REFERENCES}

[1] M. Klein, G. J. Rogers, and P. Kundur, "A Fundamental Study of Inter-Area Oscillations," IEEE Trans. on Power Systems, vol. 6, no. 3, pp. 914-921, 1991.

[2] P. Shamsollahi, O. P. Malik, "Direct neural adaptive control applied to synchronous generator," IEEE Trans. On Ene. Conv., vol. I4, no. 4, pp. 1341-1346, 1999.

[3] A. Murdoch, et al., "Integral ofaccelerating power type PSS.I. Theory, design, and tuning methodology," IEEE Transactions on Energy Conversion, vol. 14, no. 4, pp. 1658-1663, 1999.

[4] X. F. Wang, W. L. Fang, and Z. C. Du, "Modern Power System Analysis," 1st ed. Science Press: Beijing, pp. 399-420, 2003.

[5] R. Grondin, et al., "Modeling andclosed-loop validation of a new PSS concept, the multi-band PSS," IEEE Power Engineering Society General Meeting, vol. 3, pp. 13-17, 2003.

[6] I. Kamwa, R. Grondin, and G. Trudel, "IEEE PSS2B versus PSS4B: the limits ofperformance of modern power system stabilizers," IEEE Transactionson Power Systems, vol. 20, no. 2, pp. 903-915, 2005.

[7] K. Kiyong and R. C. Schaefer, "Tuning a PID controller for a digital excitation controlsystem," IEEE Transactions on Industry Applications, vol. 41, pp. 485-492, 2005.

[8] Liao Quing_n, Liudichen, Zeng Cong, Ying Liming, Cui Xue., "Eigen value sensitivitiesof excitation system, model and parameters," 3rd IEEE Conf. On IndustrialElectronics and Applications, pp. 2239-2243, 2008.

[9] W. B. Chu, J. M. Liu, J. Z. Liu, and L. X. Tan, "Modeling and Simulationabout Included New PSS of Excitation System," ElectricMachines \& Control Application, vol. 12, pp. 6-9, 2009

[10] Gurunath Gurrala, "Power System Stabilizer Design for Interconnected powerSystem," IEEE Trans. on Power Systems, vol. 25, no. 2, pp. 1042-1051, 2010.

[11] Junbo Zhang, Chung, C.Y., Shuqing Zhang, and Yingduo Han, "PracticalWide Area Damping Controller Design Based on Ambient SignalAnalysis," IEEE Transactions on Power Systems, vol. 28, no. 2, pp. 1687-1696, 2013

[12] S. Sowmya and K. Anuradha, "A novel approach to transient stability using stochastic energy functions suitable for power system risk assessment," Int. J. Eng. Sci., vol. 3, no. 1, pp. 40-47, 2014.

[13] R. Syahputra, I. Robandi, and M. Ashari, "PSO based multi-objective optimization for reconfiguration of radial distribution network," International Journal of Applied Engineering Research (IJAER), vol. 10, no. 6, pp. 14573-14586, 2015

[14] H.-F. Zhou, F. Tang, J. Jia, and X.-L. Ye, "The transient stability analysis based on WAMS and online admittance parameter identification," Proc. IEEE PowerTech Eindhoven, pp. 1-6, 2015.

[15] I. B. Sulistiawati, et al, "Critical Clearing Time prediction within various loads for transient stability assessment by means of the Extreme Learning Machine method," Int. J. Elect. Power Energy Syst., vol. 77, pp. 345-352, 2016.

[16] A. C. L. C. S. Arif., "Robust control design of PSS for dynamic stability enhancement of power system," Journal of Electrical Systems, vol. 13, no. 2, pp. 376-386, 2017.

[17] Ahmed A. Ba-muqabel, and Mohammad A. Abido, "Review of Conventional Power System Stabilizer Design Methods," IEEE GCC Conference (GCC), pp. 1-7, 2006.

[18] R. K. Pandey, and D. K. Gupta, "Performance Evaluation of Power Oscillation Damping Controller-Firefly Algorithm Based Parameter Tuning," Journal Electric Power Components and Systems, vol. 45, no. 19, pp. 2164-2174, 2017.

[19] Reza Hemmati, "Power system stabilizer design based on optimalmodel reference adaptive system," Ain Shams Engineering Journal, vol. 9, no. 2, pp. 311-318, 2018.

[20] A.A. El-Sulaiman, Z. Elrazaz, M. Barakat, "Impact of Power System Stabilizer Installation on Steady State Stability Performance," Journal of King Saud University-Engineering Sciences, vol. 2, no. 1, pp. 43-51, 1990.

[21] B. Dasu, M.S. Kumar, and R.S. Rao, "Design of robust modified power system stabilizer for dynamic stability improvement using Particle Swarm Optimization technique," Ain Shams Engineering Journal, vol. 10, no. 4, pp. 769-783, 2019. 
[22] S. Gomes, C.H.C. Guimarães, N. Martins, and G.N. Taranto, "Damped Nyquist Plot for a pole placement design of power system stabilizers," Electric Power Systems Research, vol. 158, pp. 158-169, 2018.

[23] S. Gurung, et al., "Comparative analysis of probabilistic and deterministic approach to tune the power system stabilizers using the directional bat algorithm to improve system small-signal stability," Electric Power Systems Research, vol. 181, 2020

[24] Wesley Peres, Ivo Chaves Silva Júnior, João Alberto Passos Filho, "Gradient based hybrid metaheuristics for robust tuning of power system stabilizers," International Journal of Electrical Power \& Energy Systems, vol. 95, pp. 47-72, 2018.

[25] Prasenjit Dey, Aniruddha Bhattacharya, and Priyanath Das, "Tuning of power system stabilizer for small signal stability improvement of interconnected power system," Applied Computing and Informatics, 2017.

\section{BIOGRAPHIES OF AUTHORS}
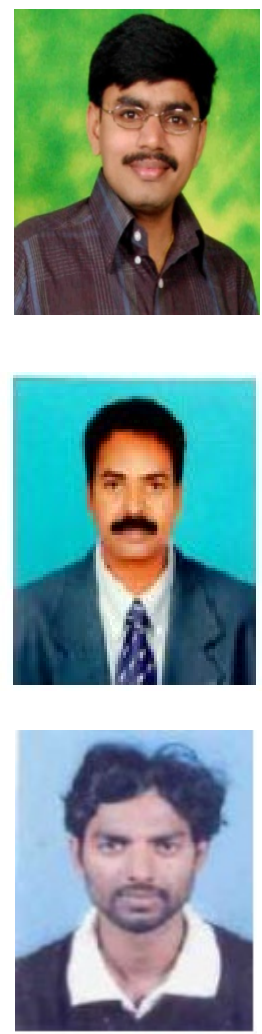

Dr. M Balasubbareddy, research focuses on Optimization Techniques, IOT, smart grid, design of Photovoltaic systems and electrical distribution analysis. He uses MATLAB programming and optimization techniques including Hardware experience design of PV systems with SCADA control. Three projects were executed with off grid and on grid systems with support of Solar Energy Corporation of India (SECI). In collaboration with a Chennai based company Industrial Controls \& Drives (India) Pvt. Ltd. (ICD), his team has developed an energy management system for integrating grid and solar power generation capacity of $400 \mathrm{kWp}$ at SV Colleges, Tirupati (Previous working College). He published significant number of referred journals in the area of Multi-objective optimization techniques and design of solar energy systems.

G V K Murthy, obtained his B.E degree in Electrical \& Electronics Engineering from UCE, Andhra University, Visakhapatnam, India in 1999. He obtained his M.Tech degree in Electrical Power Engineering from UCE, J.N.T.University, Hyderabad, India and did his Ph.D from J.N.T. University, Kakinada, India. He is presently working as Professor \& Head in the department of Electrical and Electronics Engineering in PACE Institute of Technology \& Sciences, Ongole, Andhra Pradesh, India. His areas of interest are Power Systems, Electrical Distribution Systems and Electrical machines.

K Sowjan kumar, obtained his B.Tech degree in Electrical \&Electronics Engineering from AGCET Tadepalligudem, JNTU Hyderabad, India in 2005. He obtained his M.Tech degree in Electrical Engineering from IIT, IIT Kharagpur in 2010, India. He is presently working as associate Professor in the department of Electrical and Electronics engineering, Ongole, Andhra Pradesh, India. His areas of interest are Power Systems, renewable energy sources and smart grids. 